\title{
Long-term anthropometric and metabolic evaluation of healthy newborns with intrauterine growth restriction
}

\author{
Mariana-Lacramioara Bucur-Grosu' ${ }^{1}$, Andreea-Luciana Avasiloaiei², Mihaela Moscalu ${ }^{3}$, \\ Cristina Dimitriu ${ }^{4}$, Maria Stamatin ${ }^{5}$ \\ 1"Grigore T. Popa" University of Medicine and Pharmacy, lasi, Romania \\ ${ }^{2}$ Neonatology, Department of Mother and Child Care, "Grigore T. Popa" University of Medicine and \\ Pharmacy, Iasi, Romania \\ ${ }^{3}$ Medical Informatics and Biostatistics, Department of Interdisciplinary Sciences, "Grigore T. Popa" \\ University of Medicine and Pharmacy, lasi, Romania \\ 4Biochemistry, Department of Morpho-Functional Sciences, "Grigore T. Popa" University of \\ Medicine and Pharmacy, lasi, Romania
}

\begin{abstract}
Introduction. Birth weight is the most significant anthropometric indicator of the clinical status of neonates. Intrauterine growth restriction (IUGR) is the cause of increasing death rate in neonates and is associated with adult cardiovascular disease and metabolic syndrome. The purpose of our study is to evaluate the relationship between IUGR, the development of children and metabolic complications in children up to the age of five.

Material and methods. We performed a prospective study over a period of 4 years (2010-2013) on a group of 622 newborns with IUGR without any reported conditions during the neonatal period. The nutritional status assessment was performed by determining the weight, length, body mass index and their integration according to age and sex, on the growth curves proposed by the World Health Organization and was compared to that of 627 IUGR infants admitted to the Neonatal Intensive Care Unit. The triglyceride, cholesterol and glucose levels were evaluated and compared with normal values for age.

Results. The obesity incidence $(16.1 \%)$ is significant higher $(x 2=32.23, p<<0.01,95 \% \mathrm{Cl}) .57 .6 \%$ of cases with $\mathrm{BMI}$ above the normal range, and overweight increases with age (29\% in 2-year-olds, vs. $56.7 \%$ in 5 -year-olds). The obesity incidence decreases with age (32.9\% in 2-year-old, vs. $9.1 \%$ in 5-year-olds). The evaluation of the metabolic syndrome: $18 \%$ of the investigated children had hyperglycemia, and cholesterol and triglycerides levels $(f=10.34, p=0.00001,95 \% \mathrm{Cl}$ ) increase with age. $32.8 \%$ of the evaluated children had cholesterol levels above $170 \mathrm{mg} / \mathrm{dl}$.

Conclusions. Overweight and obesity incidence among children born with IUGR are increased compared to the general population. It is necessary to establish the relationship between the eating habits and the studied parameters, that could elucidate the relationship of the increasing weight and the biochemical parameters (triglycerides and cholesterol).
\end{abstract}

Keywords: intrauterine growth restriction, obesity, overweight, metabolic syndrome, newborn

\section{INTRODUCTION}

Birth weight is an essential indicator of the clinical status of neonates. Both length and weight express the intrauterine development of the fetus, as a result of three major factors: maternal, fetal and placental. These two parameters have always been used in order to identify infants with a potential risk for the occurrence of complications in the neonatal period.

Intrauterine malnutrition is the cause of low birth size - both in terms of length and weight, it influences further development during childhood and has long term consequences on adult health (1).

If intrauterine malnutrition is associated with aggressive postnatal feeding, impaired postnatal 
growth can sometimes lead to childhood obesity and adult cardiovascular disease and metabolic syndrome. This is known as the hypothesis of fetal programming of adult disease (1-3).

The hypothesis, developed by Barker in 1988, states that there is a significant association between low birth weight and increased prevalence of obesity, hypertension, type II diabetes and cardiovascular disease among adults born with intrauterine growth restriction (IUGR). It shows the importance of postnatal growth and development of infants with IUGR, and helps to establish a care strategy in order to prevent and reduce risks by identifying and influencing the onset of these diseases during adulthood.

The purpose of our study is to evaluate the relationship between IUGR and the development of children up to the age of five, by assessing the anthropometric and metabolic complications in newborns with IUGR, with no neonatal conditions.

\section{MATERIAL AND METHODS}

We performed a prospective study over a period of 4 years (2010-2013) in "Cuza-Voda" Clinical Hospital of Obstetrics and Gynecology, in Iasi, Romania, on a group of 622 newborns with IUGR, but without any reported conditions during the neonatal period and a group of 627 IUGR infants that were admitted to the Neonatal Intensive Care Unit due to various neonatal conditions, used for comparison of nutritional dynamics.

We excluded from our study infants with severe congenital malformations and infants from twin pregnancies.

The following parameters were evaluated in both groups: gestational age, birth weight and length, gender, body mass index. In the first group we further assessed: blood glucose, triglycerides and cholesterol levels, between the ages of two and five.

IUGR was defined as a birth weight below the 3 rd percentile (on the fetal growth charts) (4).

The nutritional status assessment was performed by determining the weight and height/length and calculating the body mass index (BMI) = Weight $(\mathrm{kg}) /$ Height $(\mathrm{m})$, and their integration, ac- cording to age and sex, on the growth curves proposed by the World Health Organization (5) (Table 1).

The metabolic profile was assessed by measuring plasmatic levels of glucose, triglycerides and cholesterol, using wet chemistry on a RX Daytona $+{ }^{\circledR}$ analyzer (Randox Laboratories Ltd., Crumlin, County Antrim, UK).

Postprandial triglyceride and glucose levels were compared to the values published in the International Diabetes Federation workshop in 2007, and defined as triglyceride levels above $150 \mathrm{mg} / \mathrm{dl}$ and blood glucose level higher than $110 \mathrm{mg} / \mathrm{dl}$ (6).

The statistical analysis was performed through SPSS 20 software, using parametric tests. The reference parameter $\mathrm{p}$ represents the significance level of the test that was compared with the critical threshold value of $\mathrm{p}=0.05$, corresponding to a $95 \%$ confidence level. The results were considered significantly modified statistically for $\mathrm{p}<0.05$.

\section{RESULTS}

During 4 years, 24007 infants were born in " $\mathrm{Cu}$ za-Voda" Hospital and 1249 (5.2\%) of these were diagnosed with IUGR.

The study group included term infants, with birth weights between 2100 to 2950 grams and birth lengths between 45 to $52 \mathrm{~cm}$ (Table 2). The results showed a higher frequency $(62.38 \%)$ of healthy female newborns with IUGR $\left(\chi^{2}=9.55\right.$, $\mathrm{p}=0.002,95 \% \mathrm{CI}$ ).

The evaluation of the children nutritional status at 2-5 years of age showed that obesity prevalence in the group of former healthy IUGR newborns $(16.1 \%)$ was significantly higher compared to sick IUGR infants $-4.8 \%\left(\chi^{2}=32.23, \mathrm{p}<<0.01,95 \% \mathrm{CI}\right)$. There is a high proportion of cases $(57.6 \%)$ with BMI above the normal range in healthy newborn infants with IUGR. The analysis of children that were born with IUGR, but without any reported conditions during the neonatal period, showed that the prevalence of overweight increases with age: from $16 \%$ at the age of 2 to $56.7 \%$ at the age of 5 , but the prevalence of obesity decreases with age $(32.9 \% \mathrm{t}$ the age of 2 vs. $9.1 \%$ at the age of 5$)$ (Fig. 1). Regarding IUGR infants that were admit-

TABLE 1. Definition of obesity and overweight by age and gender

\begin{tabular}{|l|c|c|c|c|}
\hline & Gender & Age 2 years & Age 3 years & Age 4 years \\
\hline \multirow{2}{*}{ Overweight } & $\mathrm{F}$ & $\mathrm{BMI}=18-18.6$ & $\mathrm{BMI}=17.1-18.3$ & $\mathrm{BMI}=16.8-18.4$ \\
\cline { 2 - 5 } & $\mathrm{M}$ & $\mathrm{BMI}=18.1-18.7$ & $\mathrm{BMI}=17.4-18.4$ & $\mathrm{BMI}=17-18.1$ \\
\hline \multirow{2}{*}{ Obesity } & $\mathrm{F}$ & $\mathrm{BMI}>18.7$ & $\mathrm{BMI}>18.4$ & $\mathrm{BMI}>18.5$ \\
\cline { 2 - 5 } & $\mathrm{M}$ & $\mathrm{BMI}>18.8$ & $\mathrm{BMI}>18.5$ & $\mathrm{BMI}>18.2$ \\
\hline
\end{tabular}


TABLE 2. Statistical indicators of anthropometrical parameters at birth

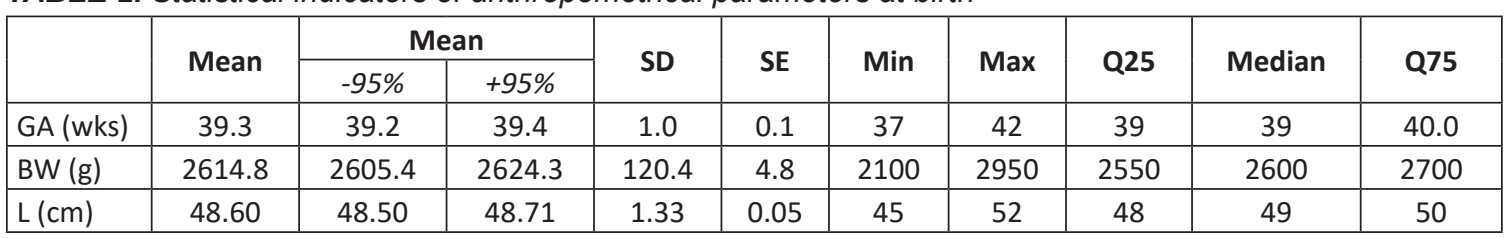

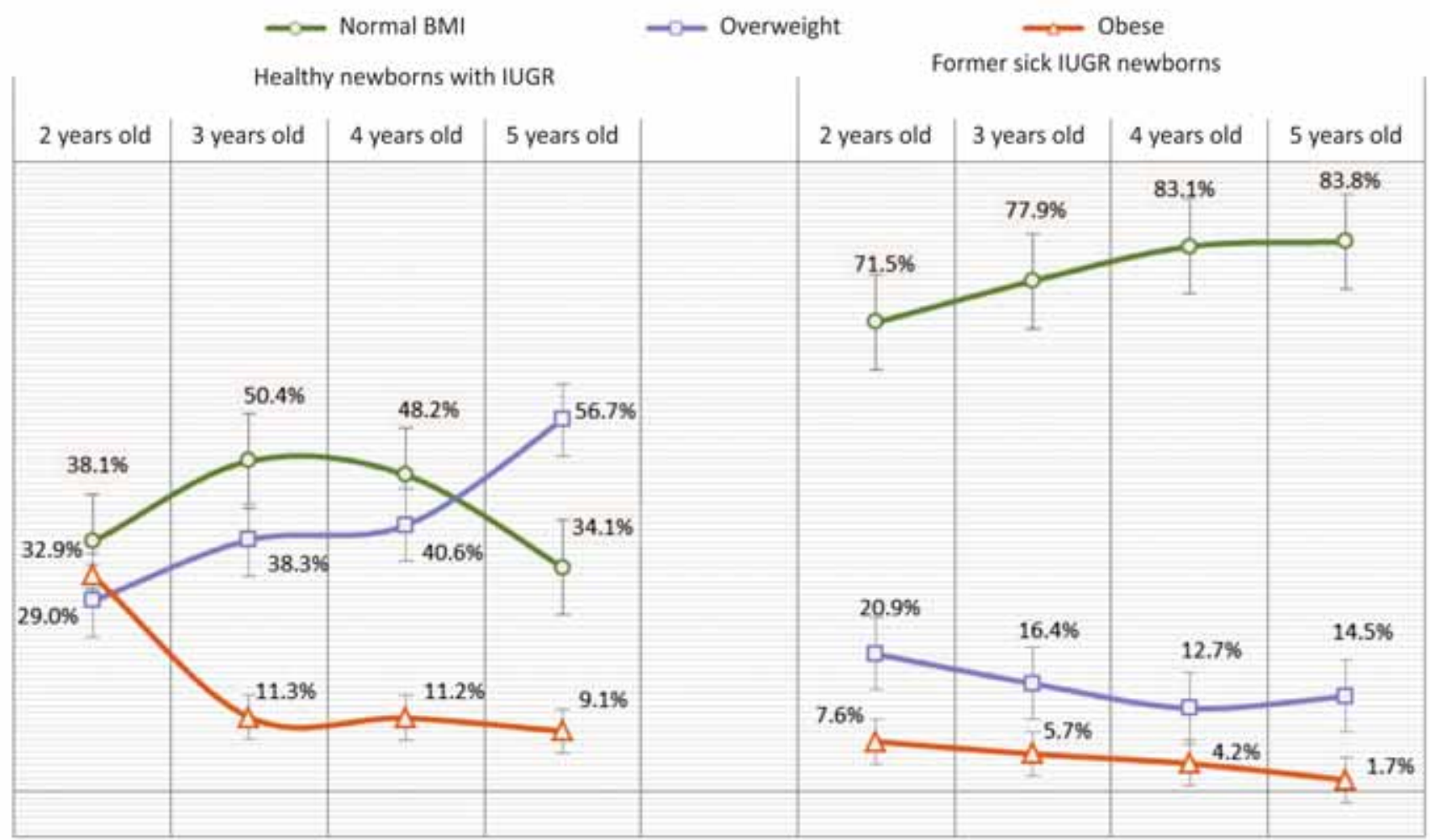

FIGURE 1. Assessment of nutritional status according to the age at the time of evaluation

ted to the Neonatal Intensive Care Unit, the percent of those with high BMI is $18.1 \%$, as both incidence of obesity and overweight decrease over time $(7.6 \%$ at the age of two to $1.7 \%$ at the age of 5 , and $20.9 \%$ to $14.5 \%$, respectively).

Analysis of the BMI values in former healthy IUGR newborns shows that $43.4 \%$ of them have a BMI above normal values. The average value was $16.8 \pm 1.54 \mathrm{SD}$, minimum and maximum values are 11.1 and 25 (Table 3).

At the age of 2 the BMI values were between 13.5 to 25 , with a mean of 17.7. During the next two years BMI decreases, but increases again by the age of 5 . In the study group, the overweight prevalence doubles between the ages of 2 and 5, even though obesity decreases.
BMI values were significantly higher at the age of 3, showing a significant decrease with age $(\mathrm{F}=14.52, \mathrm{p}<<0.01,95 \% \mathrm{CI}$ ) (Fig. 2).

Triglyceride levels increase significantly in former healthy newborns with IUGR. Also, cholesterol levels increase significantly after the age of 3 ; the average values are higher the maximum limit of the normal range $(170 \mathrm{mg} / \mathrm{dl})$.

Most of the investigated children had blood glucose levels situated in the normal range (80-100 $\mathrm{mg} / \mathrm{dl}) .18 \%$ of the children born IUGR, without neonatal conditions, had hyperglycemia, and $2.5 \%$ of the cases were at the lower limit of the normal blood sugar range $(70 \mathrm{mg} / \mathrm{dl})$. The highest values of the blood sugar levels, but within the normal range,

TABLE 3. Statistical indicators of BMI in children born with IUGR and no neonatal condition

\begin{tabular}{|l|c|c|c|c|c|c|c|c|c|}
\hline \multirow{2}{*}{$\begin{array}{l}\text { Mean } \\
\text { BMI }\end{array}$} & \multicolumn{2}{|c|}{ Mean } & \multirow{2}{*}{ SD } & SE & Min & Max & Q25 & Median & Q75 \\
\cline { 2 - 6 } & $-95 \%$ & $+95 \%$ & & & & & & \\
\hline 16.82 & 16.63 & 17.01 & 1.54 & 0.10 & 11.10 & 25.00 & 15.80 & 16.80 & 17.60 \\
\hline
\end{tabular}




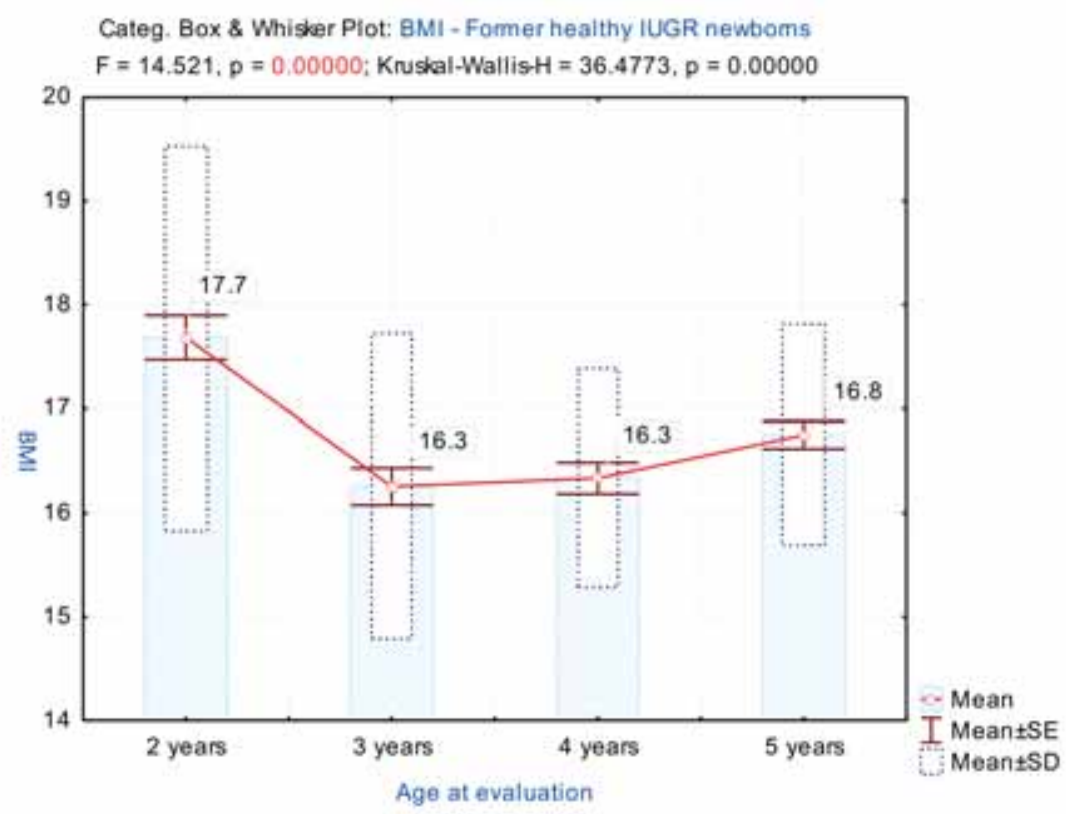

FIGURE 2. BMI distribution by age

TABLE 4. Statistical indicators of biochemical parameters in former healthy IUGR newborns

\begin{tabular}{|l|c|c|c|c|c|c|c|c|c|c|}
\hline & \multirow{2}{*}{ Mean } & \multicolumn{2}{|c|}{ Mean } & \multirow{2}{*}{ SD } & \multirow{2}{*}{ SE } & \multirow{2}{*}{ Min } & \multirow{2}{*}{ Max } & \multirow{2}{*}{ Q25 } & \multirow{2}{*}{ Median } & \multirow{2}{*}{ Q75 } \\
\cline { 3 - 9 }$n$ & & $-95 \%$ & $-95 \%$ & & & & & & & \\
\hline Blood glucose & 87.3 & 84.9 & 89.7 & 10.6 & 1.2 & 70.0 & 123.0 & 79.5 & 88.0 & 92.0 \\
\hline Triglycerides & 59.5 & 53.5 & 65.5 & 25.9 & 3.0 & 29.0 & 150.0 & 43.0 & 48.0 & 67.0 \\
\hline Cholesterol & 144.5 & 136.9 & 152.1 & 32.6 & 3.8 & 100.0 & 197.0 & 110.0 & 144.0 & 178.0 \\
\hline
\end{tabular}

were detected in 3-year-olds and decreased by the age of five (Fig. 3).

The ranges of triglyceride levels with the highest incidence in the study group were included in the range of $40-80 \mathrm{mg} / \mathrm{dl} .13 .8 \%$ of the children born IUGR, without neonatal conditions, presented triglyceride levels higher than $80 \mathrm{mg} / \mathrm{dl}$.

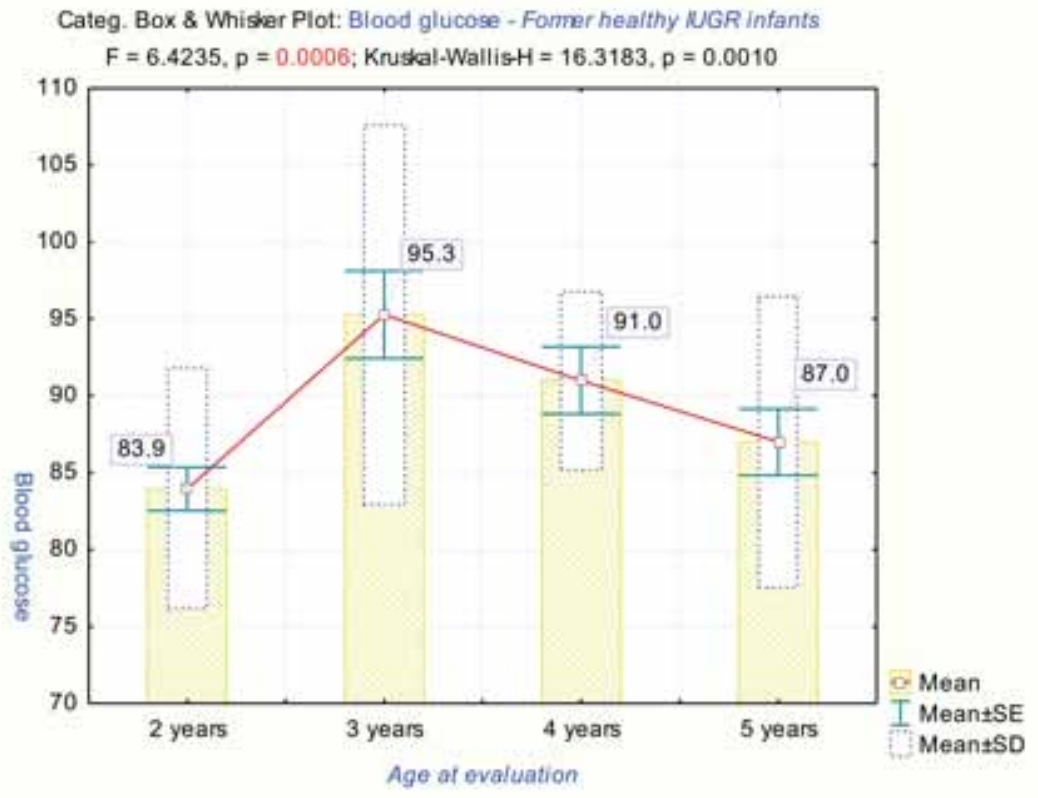

FIGURE 3. Average blood glucose levels in children born IUGR, without neonatal conditions 


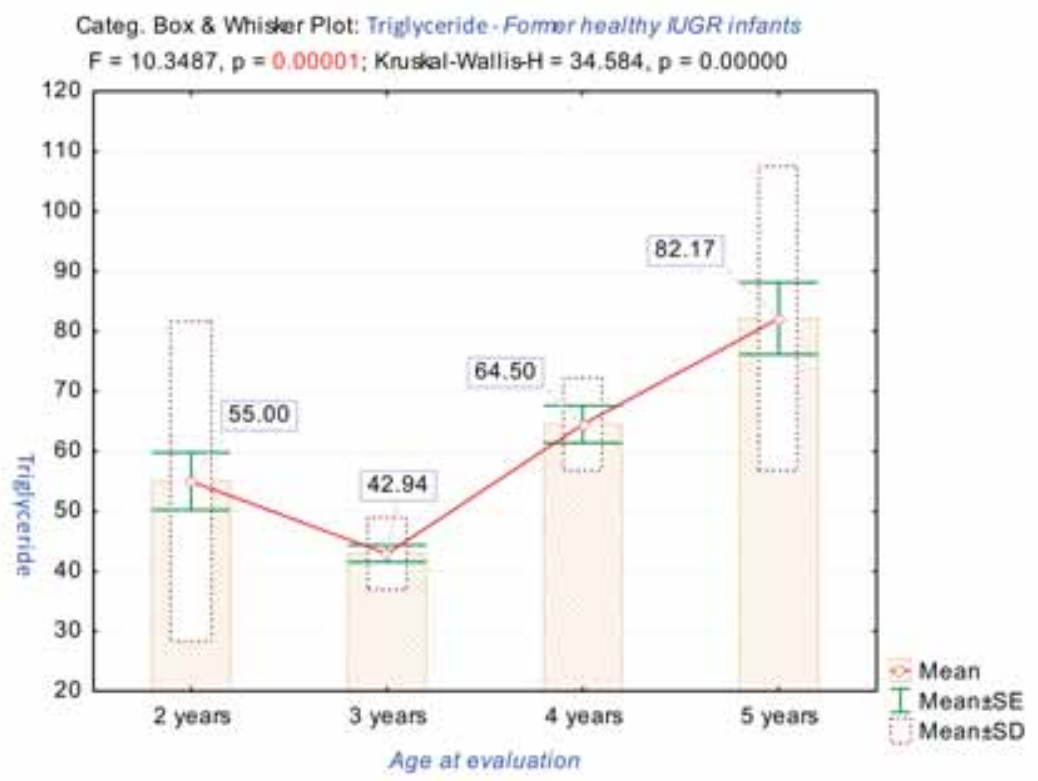

FIGURE 4. Average triglycerides levels in children born IUGR, with no neonatal condition

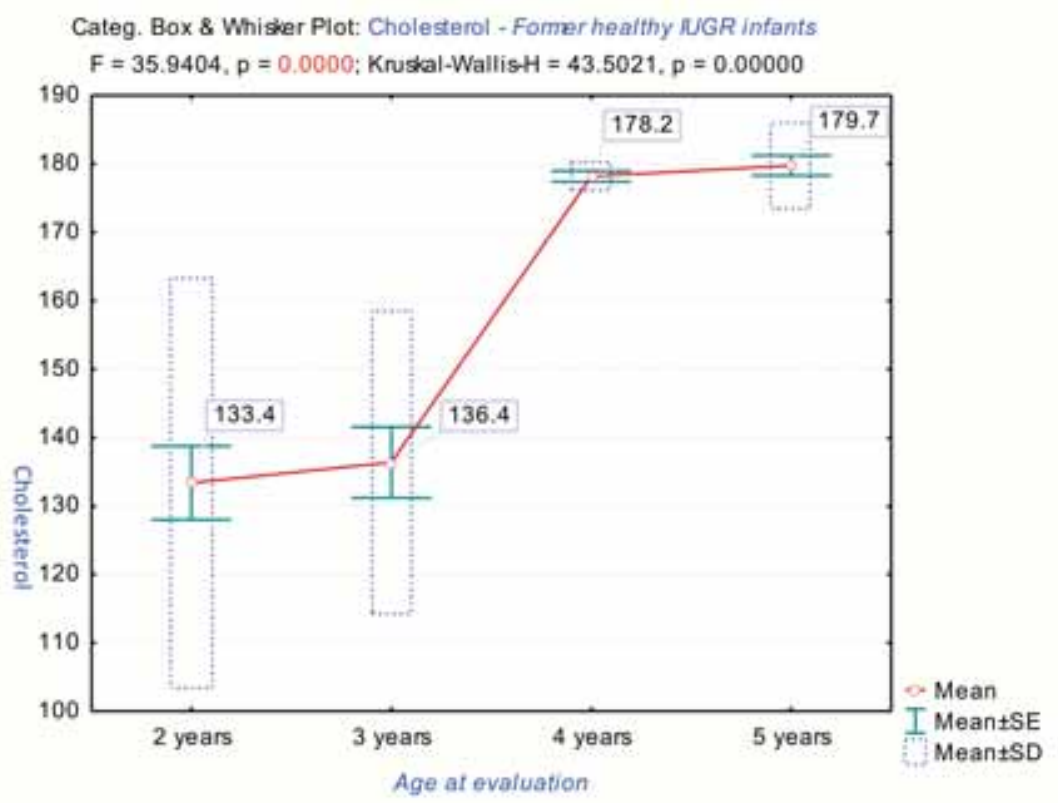

FIGURE 5. Average cholesterol levels in children born IUGR, without neonatal conditions

The lowest values are recorded in 3-year-olds (43 $\mathrm{mg} / \mathrm{dl}$ ), but tend to double by the time the infants reach the age of $5(82 \mathrm{mg} / \mathrm{dl})$. This increase is statistically significant $(\mathrm{F}=10.34, \mathrm{p}=0.00001$, 95\%CI) (Fig. 4).

The analysis of cholesterol levels reveals that $32.8 \%$ of the children born IUGR, without neonatal conditions, had cholesterol levels higher than 170 $\mathrm{mg} / \mathrm{dl}$. The mean cholesterol values were lower at the ages of 2 and 3, but rose dramatically $(\mathrm{F}=35.94$, $\mathrm{p}<<0.001)$, by more than $40 \mathrm{mg} / \mathrm{dl}$, at the ages of 4 and 5 (Fig. 5).

\section{DISCUSSIONS}

The incidence of cases with IUGR in our study group was $5.2 \%$, which is within the European standard range (between $4.6 \%$ and 15.3\%) (7-12). Risk factors for IUGR are sometimes preventable and include: genetic predisposition, preconceptional maternal nutritional status, maternal weight gain during pregnancy, social and economic status, maternal tobacco and alcohol use, pollution (13). Despite prophylaxis, IUGR has a constant incidence and long-term consequences can be serious. 
The percentage of overweight children increases with age, ranging from $29 \%$ at 2 years of age to $56.7 \%$ at 5 years of age. In this particular study group, however, the incidence of obese children decreases with ageing $(32.9 \%$ at 2 years of age versus $9.1 \%$ at 5 years of age). The increase is probably gradual later, as ascertained by a study conducted in 2013 in Romania on 8-year-old children, in which the prevalence of obesity and overweight was $27.75 \%$ (14).

Therefore, a high proportion of overweight and obese children probably come from infants born with IUGR. In children 2 to 5 years of age, the incidence of overweight in this population is almost double, compared to non-IUGR infants (7). Because in this particular study group, the percentage of obese children decreases with age, we can suggest that obesity is also influenced by other factors, such as lifestyle choices and eating habits, which are not covered in our study. As a characteristic of our country, it should be mentioned that Romania is the only European Union country whose overweight population does not become obese after 64 years of age; in all the other EU countries, the obese population increases with age (6). Various studies delineate the association between overweight/obesity in children younger than 5 years and overweight/obesity in adults, underlining the negative influence of the raised anthropometric indices at the age of 2 and the direct causal relationship with obesity in adults $(15,16)$.

$18 \%$ of the subjects presented blood sugar levels that were at the upper limit of normal, while $2.5 \%$ of the subjects were recorded at the lower limit value. During the study, none of the subjects was diagnosed with type 1 diabetes.

\section{REFERENCES}

1. Barker D.J.P., Godfrey K.M. The developmental origins of adult disease. Am J Nutr. 2004; 23:588-95.

2. Barker D.J.P., Gluckman P.D., Gofrey K.M., Harding J.E., Owen J.A., Robinson J.S. Fetal nutrition and cardiovascular disease in adult life. Lancet 1996; 341: 1478-80.

3. Langley-Evans S.C. Developmental programming of health and disease. Proc Nutr Soc. 2006; 65(1):97-105.

4. Lubchenco L.O., Hansman C., Boyd E. Intrauterine growth as estimated from live born birth-weight data 24-42 weeks of gestation. Pediatrics 1963; 32: 793-823.

5. http://www.who.int/growthref/who2007 bmi for age/en/.

6. Zimmet P., Alberti G., Kaufman F., Tajima N., Silink M., Arslanian S., Wong G., Bennett P., Shaw J., Caprio S. The metabolic syndrome in children and adolescents: the IDF consensus 2007. Pediatr Diabetes 2007;8(5):299-306

7. Chiavaroli V., Marcovecchio M.L., de Giorgis T., Diesse L., Chiarelli F., Mohn A. Progression of cardio-metabolic risk factors in
Hyperglycemia during childhood is one of the most important comorbidities, and, if it is associated with obesity, increases the risk of mortality in early adulthood (6).

Serum cholesterol and triglycerides were within normal limits in our study, but showed an increase with age. Studies on adolescent and adult populations do not demonstrate a direct correlation between the increased values of these two parameters and early mortality, but their key role in increasing the incidence and severity of cardiac disease (1719).

\section{CONCLUSIONS}

Overweight and obesity incidence among children born with IUGR are increased compared to the incidence found in general population, and the increase is more pronounced with age.

In the 2 to 5 -year-old population, blood glucose values do not increase with age. Both triglycerides and cholesterol show increase with age, but maintain within normal ranges.

The study period should be extended at least until adolescence, in order to follow the evolution of these subjects and to detect the early complications of the metabolic syndrome.

Obesity and metabolic syndrome are regulated epigenetically, starting from in utero nutrition and continuing with postnatal feeding of infants and toddlers. It is therefore necessary to further study the relationship among eating habits, increasing weight, and biochemical parameters.

\section{Conflict of interest: none declared Financial support: none declared}

subjects born small and large for gestational age. PLoS One. 2014;9(8):104-278.

8. Ruiz M., Goldblatt P., Morrison J., Kukla L., Svancara J., RiittaJarvelin M. et al. Mother's education and the risk of preterm and small for gestational age birth: a drivers meta-analysis of 12 European cohorts. J Epidemiol Community Health. 2015; 69(9):826-33.

9. Black R.E. Global prevalence of small for gestational age births. Nestle Nutr Inst Workshop Ser. 2015;81:1-7.

10. Lee A.C., Katz J., Blencowe H., Cousens S., Kozuki N., Vogel J.P. et al. National and regional estimates of term and preterm babies born small for gestational age in 138 low-income and middle-income countries in 2010. Lancet Glob Health 2013;1(1):26-36.

11. Lee P.A., Chernausek S.D., Hokken-Koelega A.C., Czernichow P. International Small for Gestational Age Advisory Board consensus development conference statement: management of short children born small for gestational age, April 24-October 1, 2001. Pediatrics 2003: 111:1253-61. 
12. Chiavaroli V., Castorani V., Derraik J.G.B., Liberati M., Chiarelli F., Mohn A. Incidence of infants born small- and large-for-gestationalage in an Italian cohort over a 20 -year period and associated risk factors. Ital J Pediatr. 2016; 46

13. Cetin I., Mandò C., Calabrese S. Maternal predictors of intrauterine growth restriction. Curr Opin Clin Nutr Metab Care. 2013; 16(3):310-9

14. Ministerul Sănătății, 2014, Copiii români sunt normoponderali; http:// www.ms.ro/?pag=62\&id=13342\&pg=1

15. Van Jaarsveld C.H.M., Gulliford M.C. Childhood obesity trends from primary care electronic health records in England between 1994 and 2013: population-based cohort study. Arch Dis Child 2015;100:214-9

16. Perng W., Hajj H., Belfort M.B., Rifas-Shiman S.L., Kramer M.S., Gillman M.W., Oken E. Birth size, early life weight gain, and midchildhood cardiometabolic health. J Pediatr. 2016; 173:122-30.

17. Franks P.W., Hanson R.L., Knowler W.C., Sievers M.L., Bennett P.H., Looker H.C. Childhood obesity, other cardiovascular risk factors, and premature death N Engl J Med. 2010; 362:485-93.

18. Pavkov M.E., Bennett P.H., Knowler W.C., Krakoff J., Sievers M.L., Nelson R.G. Effect of youth-onset type 2 diabetes mellitus on incidence of end-stage renal disease and mortality in young and middle-aged Pima Indians. J Am Med Assoc. 2006; 296:421-6

19. Third Report of the National Cholesterol Education Program (NCEP) Expert Panel on Detection, Evaluation, and Treatment of High Blood Cholesterol in Adults (Adult Treatment Panel III): final report. Circulation 2002;106:3143-421 